\title{
Preparation and characterization of isotactic polypropylene/zinc oxide microcomposites with antibacterial activity
}

\author{
Clara Silvestre ${ }^{1}$, Sossio Cimmino ${ }^{1}$, Marilena Pezzuto ${ }^{1}$, Antonella Marra ${ }^{2}$, Veronica Ambrogi ${ }^{2}$, \\ Jeannette Dexpert-Ghys ${ }^{3}$, Marc Verelst ${ }^{3}$, Sylvain Augier ${ }^{4}$, Ida Romano ${ }^{5}$ and Donatella Duraccio ${ }^{1}$
}

In this study, we investigated the influence of $\mathrm{ZnO}$ particles obtained by spray pyrolysis with submicron dimensions on the structure, morphology, thermal stability, photodegradation stability, mechanical and antibacterial properties of isotactic polypropylene (iPP)/ZnO composites prepared by melt mixing. The results of the morphological analyses indicate that, despite the surface polarity mismatch between iPP and $\mathrm{ZnO}$, the extrusion process and the unique characteristics of the utilized particles allow a composite with a fair distribution of particles to be obtained, although some agglomeration phenomena can occur, which primarily depends on the composition of the composite. The addition of $\mathrm{ZnO}$ particles imparts significant improvements on the photodegradation resistance of iPP to ultraviolet irradiation, which confirms that $\mathrm{ZnO}$ particles act as screens for this type of radiation. The thermal stability of the iPP/ZnO composites is improved with respect to that of neat iPP and increases with the content of ZnO. The iPP/ZnO composites exhibit significant antibacterial activity against Escherichia coli. This activity is dependent on exposure time and composition.

Polymer Journal (2013) 45, 938-945; doi:10.1038/pj.2013.8; published online 13 February 2013

Keywords: antimicrobial activity; composite materials; photodegradation; polypropylene; properties; spray pyrolysis; ZnO particles

\section{INTRODUCTION}

The interest in polymer materials with enhanced properties that exhibit antimicrobial activity is continuously increasing because of the growing demand for healthy living. The potential fields of application for these materials include, for instance, textiles, ${ }^{1,2}$ food packaging ${ }^{3}$ or medical devices to prevent infection. ${ }^{4}$ The use of inorganic antibacterial nano- and micro-particles has several advantages over organic agents, ${ }^{5,6}$ including thermal resistance, chemical stability, safety and a longer active period. ${ }^{3,7,8}$ Silver, gold and zinc nanoparticles are the most studied nanoparticles, and silver nanoparticles have already been used in several commercial applications. Nanoscale silver, which possesses high temperature stability and low volatility, is known to be an effective antifungal and antimicrobial material, and it has been reported to be effective against 150 different bacteria. ${ }^{9}, 10$ Titanium dioxide $\left(\mathrm{TiO}_{2}\right)$, zinc oxide $(\mathrm{ZnO})$, silicon oxide $\left(\mathrm{SiO}_{2}\right)$ and magnesium oxide $(\mathrm{MgO})$ have been investigated for their ability to be used as ultraviolet (UV) blockers and photo-catalytic disinfecting agents, ${ }^{11}$ and they are considered to be safe materials for human beings and animals. ${ }^{12}$ More recently, the antimicrobial properties of nanoscale $\mathrm{ZnO}$ and $\mathrm{MgO}$ have been discovered. Compared with nanosilver, the nanoparticles of $\mathrm{ZnO}$ and $\mathrm{MgO}$ are expected to provide more affordable and safe solutions in the future. Nanomaterials containing a nano-ZnO-based photocatalyst, which has been reported to sterilize indoor lighting, have been recently introduced. It has been reported that $\mathrm{ZnO}$ exhibits antibacterial activity that increases with decreasing particle size. ${ }^{13}$ This activity does not require the presence of UV light (unlike $\mathrm{TiO}_{2}$ ), but it is stimulated by visible light. ${ }^{14}$ In particular, the use of $\mathrm{ZnO}$ has been viewed as a viable solution for stopping infectious diseases because of its antimicrobial properties. ${ }^{15}$ The intrinsic properties of a metal nanoparticle are primarily determined by its size, shape, composition, crystallinity and morphology. ${ }^{16} \mathrm{ZnO}$ particles have been incorporated into a number of different polymers, including low density polyethylene (LDPE) ${ }^{17,18}$ isotactic polypropylene (iPP), ${ }^{19-23}$ polyvinyl acetate (PVA), ${ }^{24}$ polyammide (PA ${ }^{25}$ and cotton woven fabric, ${ }^{26}$ for more than antimicrobial purposes.

For example, in Low Density Polyethylene/ZnO composites prepared using the melt-mixing process, $\mathrm{ZnO}$ powders (sizes of 200 and $2 \mathrm{~mm}$ ) were used as reinforcing particles for improving the dielectric and conductivity properties of the composite. ${ }^{17}$ Polyvinyl acetate/ZnO nanocomposites have potential applications as a photoanode in

${ }^{1}$ Istituto di Chimica e Tecnologia dei Polimeri (ICTP)-CNR, Pozzuoli, Italy; ${ }^{2}$ Università di Napoli 'Federico II', Dipartimento Di Ingegneria Dei Materiali E Della ProduzionePiazzale Tecchio, Napoli, Italy; ${ }^{3}$ CEMES-CNRS, Toulouse Cedex 4, France; ${ }^{4}$ Pylote SAS, Chemin de la Loge, Toulouse Cedex 4, France and ${ }^{5}$ Istituto di Chimica Biomolecolare (ICB)-CNR, Pozzuoli, Italy

Correspondence: Dr D Duraccio, Istituto di Chimica e Tecnologia dei Polimeri (ICTP)-CNR, Via Campi Flegrei 34, 80078 Pozzuoli, Napoli, Italy. E-mail: duraccio@ictp.cnr.it

Received 3 September 2012; revised 3 December 2012; accepted 5 December 2012; published online 13 February 2013 
high-efficiency dye-sensitized solar cells, light-emitting diodes, lasers, field-emission devices and chemical sensors. ${ }^{20}$ Nano-ZnO coated cotton fabric ${ }^{24}$ has been observed to exhibit antimicrobial properties against Staphylococcus aureus and E. coli in both qualitative and quantitative tests. Antimicrobial activity has also been observed for Low Density Polyethylene and PA6/ZnO composites. ${ }^{18}$

iPP is one of the most important commercial polymers due to its low price and an attractive combination of good processability, mechanical properties and chemical resistance. ${ }^{27,28}$ Furthermore, iPP films are used in packaging applications because of their strength, transparency brilliance, low specific weight and high chemical inertness. ${ }^{29,30}$ Compounding iPP with inorganic particles is an effective method for improving the properties of iPP. ${ }^{31-33}$ Zhao and $\mathrm{Li}^{19}$ investigated the use of $\mathrm{ZnO}$ as an ultraviolet absorber in iPP. Huang et al. ${ }^{20}$ added $\mathrm{ZnO}$ nanopowder through microinjection molding to investigate the mechanical properties of iPP. Lepot et al. $^{21}$ have investigated the effects of the concentration and shape of $\mathrm{ZnO}$ on the processing and properties of biaxially oriented polypropylene- $\mathrm{ZnO}$ nanocomposites. Tang et al. ${ }^{23}$ reported that $\mathrm{ZnO}$ is a good nucleating agent and that $\mathrm{ZnO}$ nanoparticles coated with organic nucleating agents affect the morphology and crystallization of iPP. In this article, $\mathrm{iPP} / \mathrm{ZnO}$ composites were prepared using the melt-mixing technique. $\mathrm{ZnO}$ particles with submicron dimensions have been obtained at the pilot scale using spray pyrolysis. ${ }^{34}$ This technique offers specific advantages compared with other material processing techniques, such as gas-to-particle conversion processes and liquid or solid-state processing followed by milling. These advantages are a higher purity of the produced powders, a better uniformity in the chemical composition, a narrower size distribution, a better regularity in shape (spherical) and the synthesis of multicomponent materials. Another significant advantage to be noted is the relative simplicity of the process, which could allow scale-up, such as that recently performed by the PYLOTE company. ${ }^{35,36}$

The primary objective of this study is to investigate the influence of $\mathrm{ZnO}$ microparticles on the morphology, photodegradation stability and antibacterial activity of $\mathrm{PP} / \mathrm{ZnO}$ composites. The analysis of the mechanical properties completes the characterization of these materials. This paper is the first of a series that aims to exploit the potential of iPP/ZnO-based composites. In the following paper, the influence of compatibilizing agents based on polypropylene grafted with maleic anhydride and of the processing conditions to improve the particles dispersion will be reported.

\section{EXPERIMENTAL PROCEDURE}

\section{Materials and sample preparation}

The zinc oxide particles were produced using a preindustrial scale spray pyrolysis platform. During the production process, droplets of a precursor solution (zinc nitrate) were dried and decomposed into the required compound. The presence of an additional soluble flux in the precursor solution permitted the formation of agglomerate-free particles after washing the product. The production rate was $\sim 100 \mathrm{gh}^{-1}$ of powders.

Before mixing, $\mathrm{ZnO}$ was dried in an oven at $100^{\circ} \mathrm{C}$ for $3 \mathrm{~h}$. Pure iPP (Moplen X30S), which was kindly supplied by Basell (Ferrara, Italy), has a melt flow index $=9 \mathrm{dg} \mathrm{min}^{-1}$ (measured at $230^{\circ} \mathrm{C}$ ), a $M_{\mathrm{w}}=3.5 \times 10^{5}$ and a $M_{\mathrm{n}}=4.7 \times 10^{4}$.

iPP and $\mathrm{ZnO}$ were compounded at the desired compositions in a $25-\mathrm{mm}$ twin-screw extruder $(\mathrm{L} / \mathrm{D}=56)$. The temperature setting of the extruder from the hopper to the die was $180 / 200 / 200 / 190 / 180^{\circ} \mathrm{C}$, and the screw speed was 25 r.p.m. The mixing ratios of $\mathrm{iPP} / \mathrm{ZnO}$ (wt/wt) were 100/0, 98/2 and 95/5.

Films of $\mathrm{PP}$ and $\mathrm{PP} / \mathrm{ZnO}$ were obtained by compression molding in a press at $210{ }^{\circ} \mathrm{C}$ and 100 bar. The mold had a rectangular shape with dimensions of $100 \times 90 \mathrm{~mm}$ and a thickness of $130 \mu \mathrm{m}$.

\section{Characterization}

Morphological characterization (scanning electron microscopy (SEM)) was performed on pellets obtained from the extruder, whereas the mechanical properties, barrier properties, UV ageing and structural analysis (WAXS) were performed on compression molded films.

Scanning electron microscopy. The surface analysis was performed using a SEM, PHILIPS model XL20, on particles of the powders and on cryogenically fractured surfaces of composites. Before the observation, samples were coated with a Au/Pd alloy using an E5 150 SEM coating unit.

Thermogravimetric Analysis. The thermal behavior of the blends was examined by thermogravimetric analysis (TGA) using a Perkin Elmer-Pyris Diamond apparatus with a heating rate of $10{ }^{\circ} \mathrm{Cmin}^{-1}$ in air. Two measurements were performed for each sample.

Mechanical tests. Dumbbell-shaped specimens were cut from the compression molded films and used for the tensile measurements. Stress-strain curves were obtained using an Instron machine (Model 4505) at room temperature $\left(25^{\circ} \mathrm{C}\right)$ at a crosshead speed of $5 \mathrm{~mm} \mathrm{~min}^{-1}$. Ten tests were performed for each composition

Photo-oxidation tests. The UV-irradiation treatments for the unfilled iPP and iPP/ZnO composite films were performed using a UV-accelerated weathering tester (Sunrise, Angelantoni Industrie ACS, Perugia, Italy, UVA $360 \mathrm{~nm}$ ), with a light intensity of $20 \mathrm{Wm}^{-2}$. Both surfaces of the films were subjected to the UV irradiation for $600 \mathrm{~h}$ at a temperature of $40{ }^{\circ} \mathrm{C}$. During the UV-irradiation treatment, the samples were subjected to Fourier transform infrared (FTIR) analysis. The molecular degradation of the samples was characterized based on the carbonyl index, which was calculated using Equation (1):

Carbonyl index $=A_{\mathrm{c}} / A_{\mathrm{r}}$

where $A_{c}$ is the area of the carbonyl absorption band (in the range of $1670-1780 \mathrm{~cm}^{-1}$ ) and $A_{\mathrm{r}}$ is the area of the reference band (in the range from $870-820 \mathrm{~cm}^{-1}$ ). The carbonyl band reflects several degradation products. The reference band is not affected by photo-oxidation nor by varying crystallinity. ${ }^{37}$

Wide-Angle X-ray Diffraction. Wide-angle X-ray diffraction (WAXD) measurements were conducted using a Philips XPW diffractometer (Philips Analytical, Almelo, The Netherlands) with $\mathrm{Cu} \mathrm{K} \alpha$ radiation ( $1.542 \AA$ ) filtered by nickel. The scanning rate was $0.02^{\circ} \mathrm{Cmin}^{-1}$, and the scanning angle was from 5 to $45^{\circ}$ (for $\mathrm{ZnO}$, from 10 to $60^{\circ}$ ). The ratio of the area under the crystalline peaks and the total area multiplied by 100 was taken as the crystalline percentage degree. Measurements were performed on compression molded films and on aged films after 300 and $600 \mathrm{~h}$ of exposure to UV radiation.

Antibacterial evaluation. The antimicrobial activity of the iPP/ZnO composites was evaluated using E. coli DSM $498^{\mathrm{T}}$ (DSMZ, Braunschweig, Germany) as test microorganisms. The evaluation was performed using the ASTM Standard Test Method E 2149-10 preparation of the bacterial inoculum required us to grow a fresh 18-h shake culture of E. coli DSM 498 in a sterile nutrient broth (LB composition for 1 1: $10 \mathrm{~g}$ of triptone, $5 \mathrm{~g}$ of yeast extract and $10 \mathrm{~g}$ of sodium chloride) The colonies were maintained according to good microbiological practice and examined for purity by creating a streak plate. The bacterial inoculum was diluted using a sterile buffer solution (composition for one liter: $0.150 \mathrm{~g}$ of potassium chloride, $2.25 \mathrm{~g}$ of sodium chloride, $0.05 \mathrm{~g}$ of sodium bicarbonate, $0.12 \mathrm{~g}$ of calcium chloride $6 \mathrm{H}_{2} \mathrm{O}$ and a pH of 7) until the solution reached an absorbance of $0.3 \pm 0.01$ at $600 \mathrm{~nm}$, as measured spectrophotometrically. This solution, which had a concentration of $1.5-3 \times 10^{8}$ colony forming units (CFUs) $\mathrm{ml}^{-1}$, was diluted with the buffer solution to obtain a final concentration of $1.5-3 \times 10^{6} \mathrm{CFUs} \mathrm{ml}^{-1}$. This solution was the working bacterial dilution.

The experiments were performed in 50-ml sterilized flasks. One gram of the film was maintained in contact with $10 \mathrm{ml}$ of the working bacterial dilution. After $2 \mathrm{~min}, 100 \mu \mathrm{l}$ of the working bacterial dilution was transferred to a test tube, which was followed by serial dilution and plating out on Petri dishes $(10 \mathrm{~mm} \times 90 \mathrm{~mm})$ in which the culture media was previously poured. The petri dishes were incubated at $35^{\circ} \mathrm{C}$ for $24 \mathrm{~h}$. These dishes represented the $T_{0}$ 
contact time. The flasks were then placed on a wrist-action shaker for $1 \mathrm{~h}\left(T_{1}\right)$, $24 \mathrm{~h}\left(T_{2}\right)$ and $48 \mathrm{~h}\left(T_{3}\right)$. The bacterial concentration in the solutions at these time points was evaluated by again performing serial dilutions and standard plate counting techniques. Three experiments were performed for each composition. The number of colonies in the petri dish after incubation was converted into the number of colonies that form a unit per milliliter (CFUs ml ${ }^{-1}$ ) of buffer solution in the flask. The percentage reduction was calculated using the following formula.

Reduction \% $\left(C F U m l^{-1}\right)=(B-A / B) \times 100$

where $A=\mathrm{CFUs} \mathrm{ml}{ }^{-1}$ for the flask containing the sample after the specific contact time and $B=\mathrm{CFUs} \mathrm{ml}^{-1}$ at $T_{0}$.

\section{RESULTS AND DISCUSSION}

\section{Structure and morphology}

The SEM micrograph clearly reveals that the $\mathrm{ZnO}$ powders obtained by spray pyrolysis (Figure 1a) are composed of spherical particles that have an average diameter of $490 \mathrm{~nm}\left(d_{50}\right)$ and a BET surface area equal to $13.5 \mathrm{~m}^{2} \mathrm{~g}^{-1}$. The X-ray diffraction pattern of the particles (Figure $1 \mathrm{~b}$ ) presents the characteristic peaks of $\mathrm{ZnO}$ with no
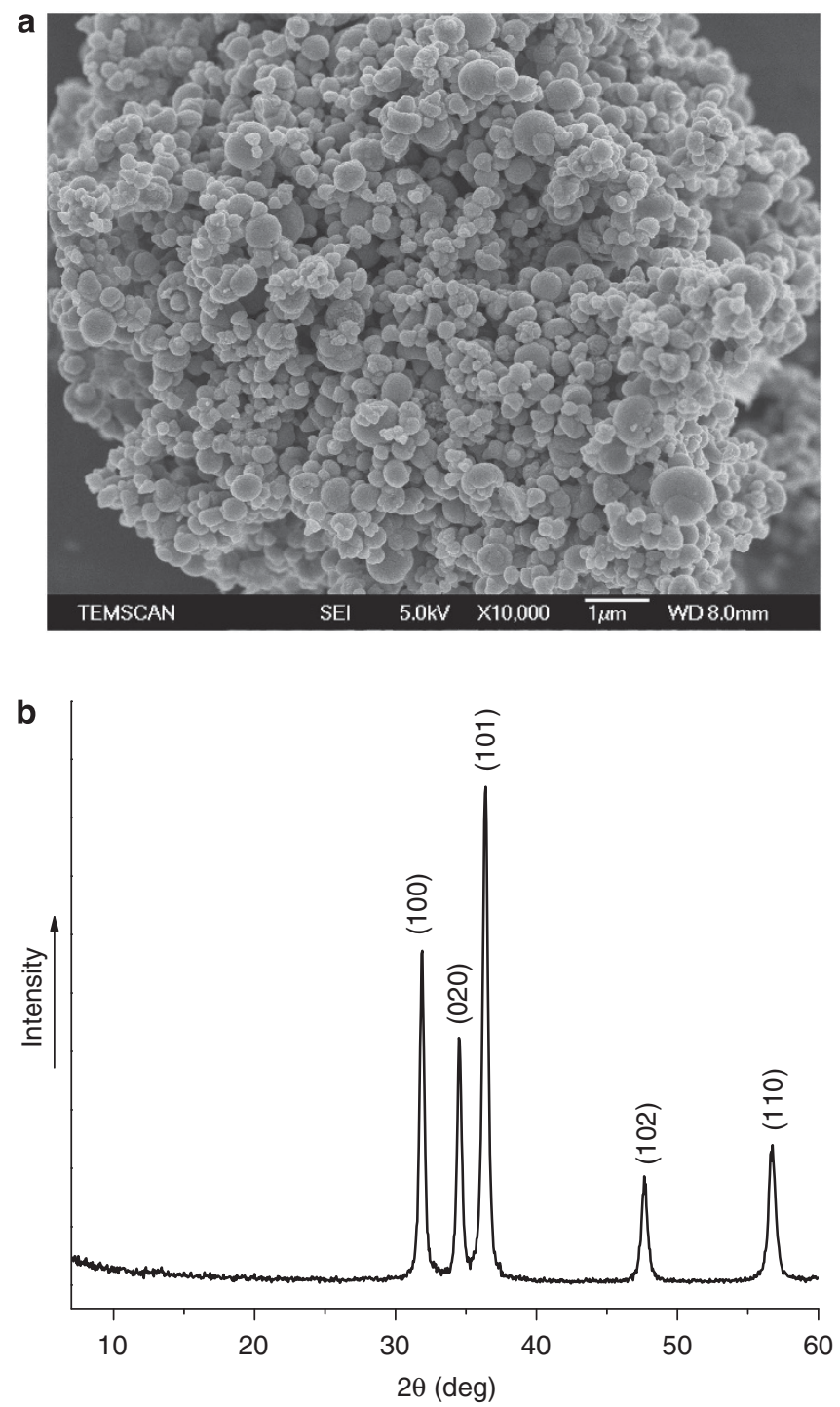

Figure 1 SEM micrograph at a magnification of $\times 10000$ (a) and wide angle diffraction pattern (b) of $\mathrm{ZnO}$ particles obtained by spray pyrolysis. unidentified peaks, which indicates that the produced particles have a high purity. The size of a single zinc-oxide crystal, which was calculated by applying the Scherrer formula ${ }^{38}$ to the reflection at $47.7^{\circ}$ for the 102 plane, is $20-25 \mathrm{~nm}$.

Figure 2a presents the SEM image of the fractured surface of the 98/2 wt/wt iPP/ZnO composite. $\mathrm{ZnO}$ is homogeneously dispersed in the iPP matrix with few agglomeration phenomena present. Moreover, a good adhesion between the phases is also evidenced by the complete absence of voids.

These results indicate that, despite the surface polarity mismatch between iPP and $\mathrm{ZnO}$, the extrusion process together with the novel particles utilized allows a composite to be obtained that has a fair distribution of particles and good adhesion between the phases.

The same features were observed for the $95 / 5 \mathrm{iPP} / \mathrm{ZnO}$ composite (Figure 2b). However, some agglomerates that were dimensionally larger than those observed for the $98 / 2 \mathrm{iPP} / \mathrm{ZnO}$ composite, are present in this blend, as shown in Figure 3. This figure shows one of these agglomerates and its interfacial adhesion with iPP.

\section{Thermodegradation analysis}

TGA measurements were performed in an air atmosphere at a heating rate of $10^{\circ} \mathrm{C} \mathrm{min}^{-1}$. The thermogravimetric curves of all the samples are shown in Figure 4. From these curves, two parameters were extracted and are reported in Table 1, which include $T_{-5 \%}$ and $T_{\max }$; the first parameter, $T_{-5 \%}$, is the temperature on the curve when the sample has lost $5 \%$ of its weight, and $T_{\max }$ is the temperature at the inflection point of the curve (detected at the maximum of the peak of the first derivative of the curve), which corresponds to the maximum rate of the degradation of the sample.

The thermogravimetric curves indicate that the thermal decomposition is a one-step process for all the samples. The $T_{-5 \%}$ values for the two composites are slightly less than that of iPP. This result indicates that the degradation of the composite begins before the degradation of iPP, which is most likely due to the catalytic effect of the metal oxide on the degradation of iPP and is consistent with results reported in the literature. ${ }^{39}$

In contrast, the $T_{\max }$ of the composites is greater $\left(352\right.$ and $382^{\circ} \mathrm{C}$, respectively) than that of plain iPP $\left(335^{\circ} \mathrm{C}\right)$ and increases with the composition, which suggests that the $\mathrm{iPP} / \mathrm{ZnO}$ composites have a greater thermal stability; this enhanced thermal stability is also evident from the shift of the curves at higher $T$, as shown in Figure 4. This behavior could be explained by hypothesizing that nano- and submicron-ZnO particles that are well dispersed in the iPP matrix (see morphological section) create a barrier labyrinth that slows the diffusion of the degradation products from the bulk of the polymer to the surface of the sample. ${ }^{40}$

\section{Photodegradation analysis}

It is well-known that the degradation of iPP can be induced by irradiation within the wavelength range of $310-360 \mathrm{~nm}^{41}$ and that it produces hydroperoxides and carbonyl species, such as ketones, esters and acids. ${ }^{42,43}$ By using FTIR spectroscopy, the degradation products induce the evolution of absorption peaks in the wavenumber ranges of $3200-3600$ and $1600-1800 \mathrm{~cm}^{-1}$.

In Figure 5, the evolutions of the FTIR spectra in the wavenumber range of $1670-1780 \mathrm{~cm}^{-1}$ are examined for samples irradiated with UV for 0,300 and $600 \mathrm{~h}$ of exposure. Comparing the FTIR spectra for iPP, the evolution of the absorption peaks within the carbonyl region is very dramatic, whereas for the composites, these peaks increase slowly. The evolution of the characteristic peaks for the photodegradation of iPP has been investigated in detail. ${ }^{44}$ At the beginning of 

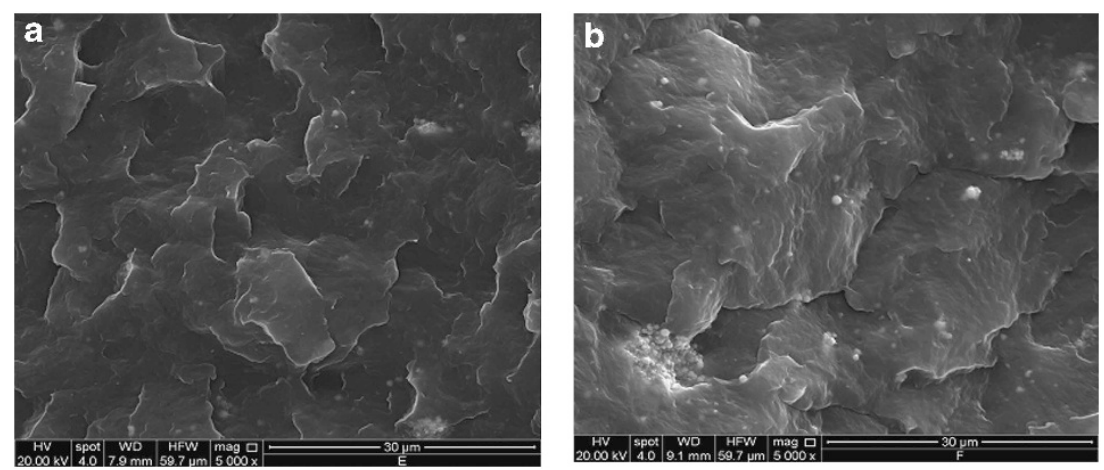

Figure 2 SEM micrographs of the fractured surface of the 98/2 iPP/ZnO (a) and 95/5 iPP/ZnO (b) composites at a magnification of $\times 5000$.

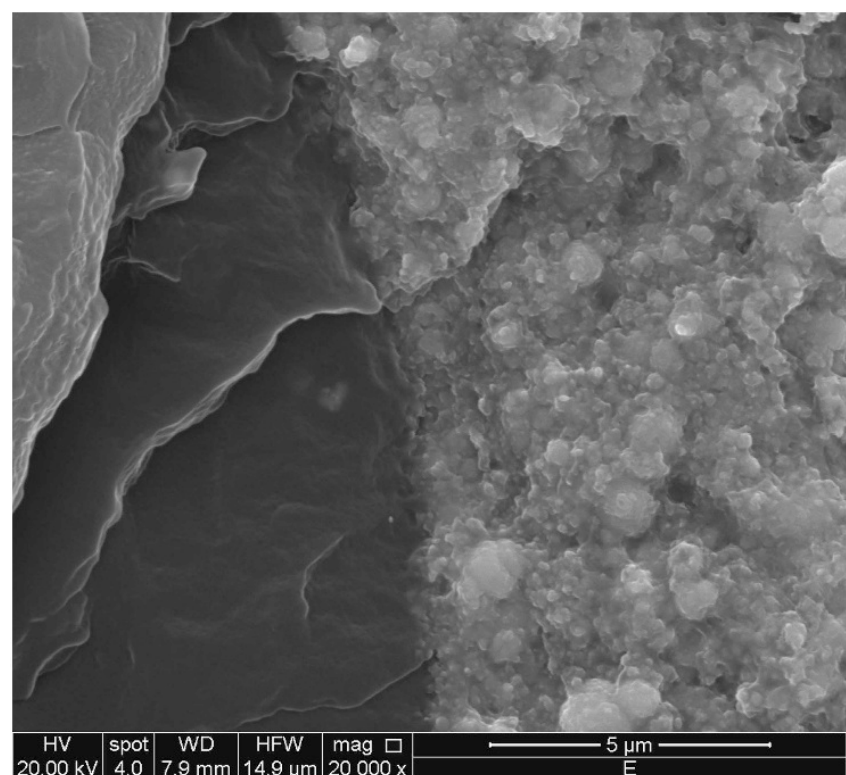

Figure 3 SEM micrographs of the fractured surface of the 95/5 iPP/ZnO composite at a magnification of $\times 20000$.

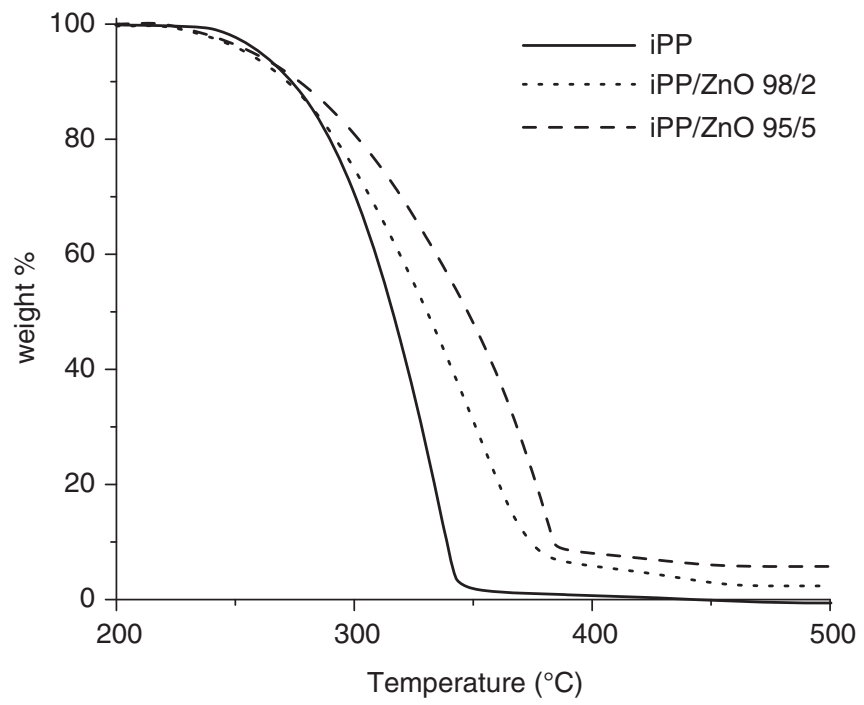

Figure 4 TGA curves for iPP and iPP/ZnO composites obtained under air.
Table $1 T_{-5 \%}\left({ }^{\circ} \mathrm{C}\right)$ and $T_{\max }\left({ }^{\circ} \mathrm{C}\right)$ measured by TGA

\begin{tabular}{lcc}
\hline & $\mathrm{T}_{-5 \%}\left({ }^{\circ} \mathrm{C}\right)$ & $\mathrm{T}_{\max }\left({ }^{\circ} \mathrm{C}\right)$ \\
\hline $\mathrm{iPP}$ & 261 & 335 \\
$\mathrm{iPP} / \mathrm{ZnO} 2 \%$ & 255 & 352 \\
$\mathrm{iPP} / \mathrm{ZnO} 5 \%$ & 257 & 382 \\
\hline
\end{tabular}

Abbreviations: ipp, isotactic polypropylene; TGA, thermogravimetric analysis.

the UV exposure period, carboxylic acid was initially formed, and with exposure periods greater than $60 \mathrm{~h}$, the formation of ketones and lactones occurs. ${ }^{45}$

For a quantitative analysis of the extent of the photodegradation, the carbonyl indices for $\mathrm{PPP}$ and $\mathrm{PP} / \mathrm{ZnO}$ composites as a function of time were calculated (Equation (1)), which are presented in Figure 6. This graph reveals that the carbonyl indices for the composites are always less than that of iPP. It can be concluded that $\mathrm{ZnO}$ particles have an important role in stabilizing the iPP molecules and delay the photodegradation process by functioning as screens that absorb the UV radiation and consequently reduce the UV intensity that results in the oxidation of the iPP chains. However, because no new peaks were observed during UV irradiation in the $\mathrm{PPP} / \mathrm{ZnO}$ composites when compared with neat iPP, the photodegradation mechanisms for all the systems should be identical. Similar outstanding photo-stabilization effects have been reported for $\mathrm{iPP} / \mathrm{ZnO},{ }^{46}$ linear low density polyethylene (LLDPE)/ZnO ${ }^{47}$ and iPP/Montmorillonite (MMT) nanocomposites. ${ }^{42,48}$

The structures of the samples before and after irradiation were investigated using WAXD. The WAXD patterns (not reported) reveal that $\mathrm{iPP}$ and the $\mathrm{iPP} / \mathrm{ZnO}$ composites always crystallize in the monoclinic $\alpha$-form. These observations are in contrast with other studies of $\mathrm{PP} / \mathrm{ZnO}$ nanocomposites in which it was shown that both nanoscale ${ }^{19,23}$ and micron $^{23} \mathrm{ZnO}$ functions as a nucleating agent for the $\beta$-form.

In Table 2, the crystallinity index, which was measured from the $\mathrm{X}$-ray diffraction patterns, is reported for all of the systems at 0,300 and $600 \mathrm{~h}$ of UV exposure. For all the samples at $0 \mathrm{~h}$, the crystallinity index referring to the iPP phase does not vary with the content of $\mathrm{ZnO}$. For iPP, after $300 \mathrm{~h}$ of UV exposure, the crystallinity index increases and then it remains constant until the end of the exposure. For the composites after $300 \mathrm{~h}$ of exposure, the crystallinity index does not significantly change, whereas it increases and becomes similar to that of iPP after $600 \mathrm{~h}$ of UV exposure.

When exposed to a source of chemical degradation, the morphology of semi-crystalline polymers may be modified, ${ }^{49}$ and in some 
cases, disruption of the crystalline order occurs as detected by a reduction in the fractional crystallinity. ${ }^{50}$ In other cases, however, the crystallinity has been reported to increase during exposure. ${ }^{51}$ It is generally accepted that the latter occurs because chemical degradation causes scission of molecular chains with the consequent release of
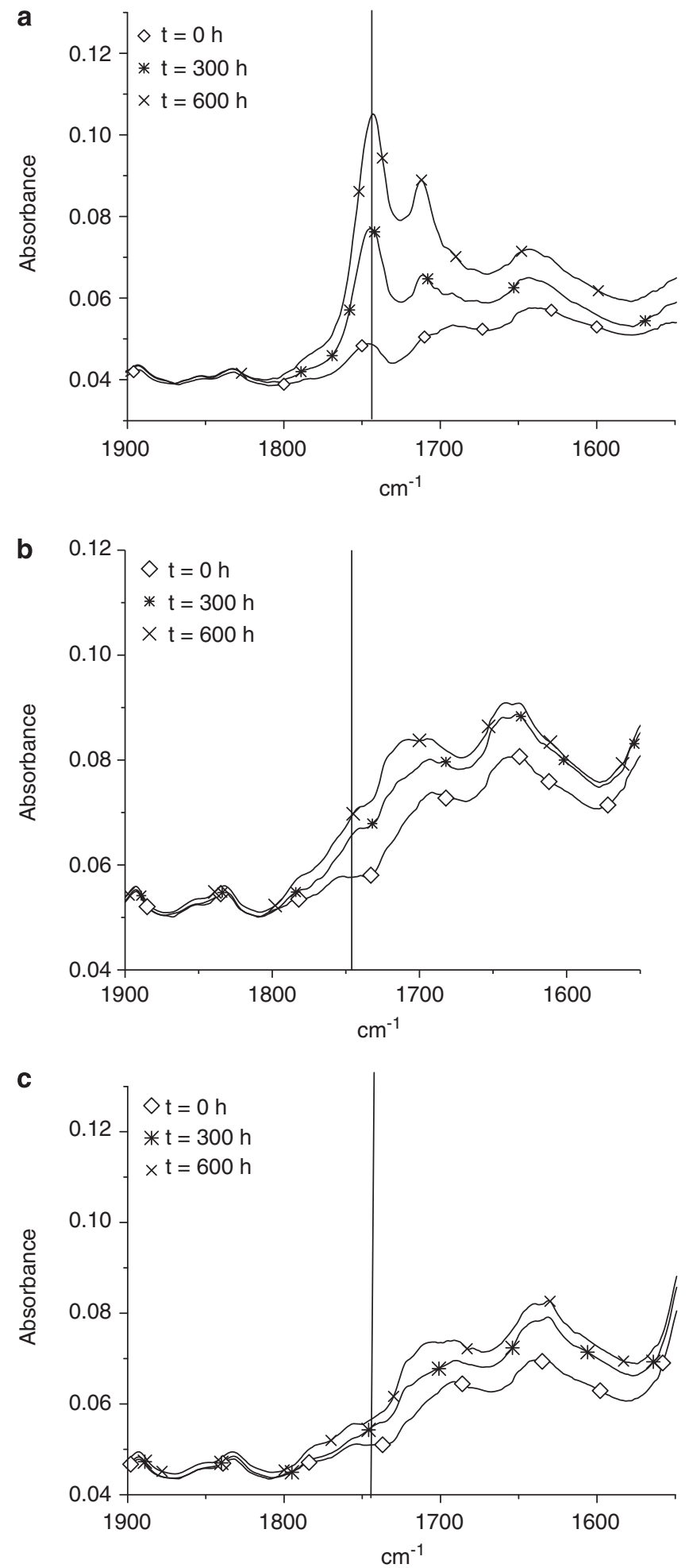

Figure 5 FTIR spectra for iPP (a), 98/2 iPP/ZnO (b) and 95/5 iPP/ZnO (c) at different UV exposure times. segments of entangled and tie chain molecules in the amorphous region that were unable to crystallize during the original solidification process. These freed segments can subsequently rearrange into a crystalline phase, provided they have sufficient mobility. This process is known as chemi-crystallization. ${ }^{52}$ The results obtained by WAXD clearly indicate, according to the FTIR results, that $\mathrm{ZnO}$ delays the chemi-crystallization of iPP.

\section{Mechanical Properties}

The tensile parameters for the composites, such as the Young's modulus, the stress and strain at the yield point and those at the break point, are presented in Table 3. iPP displays a ductile behavior, with a yield point, cold-drawing region and fiber formation region; the elongation and the stress at break were observed at almost $900 \%$ and at $\sim 30 \mathrm{MPa}$, respectively. The two composites still present a ductile behavior, but the rupture occurs during the fiber formation region at values that depend on the content of $\mathrm{ZnO}$. In fact, for the 2 and $5 \%$ filled systems, the elongation at break decreases to $640 \%$ and $500 \%$, and the stress at break decreases to 20 and $16 \mathrm{MPa}$, respectively.

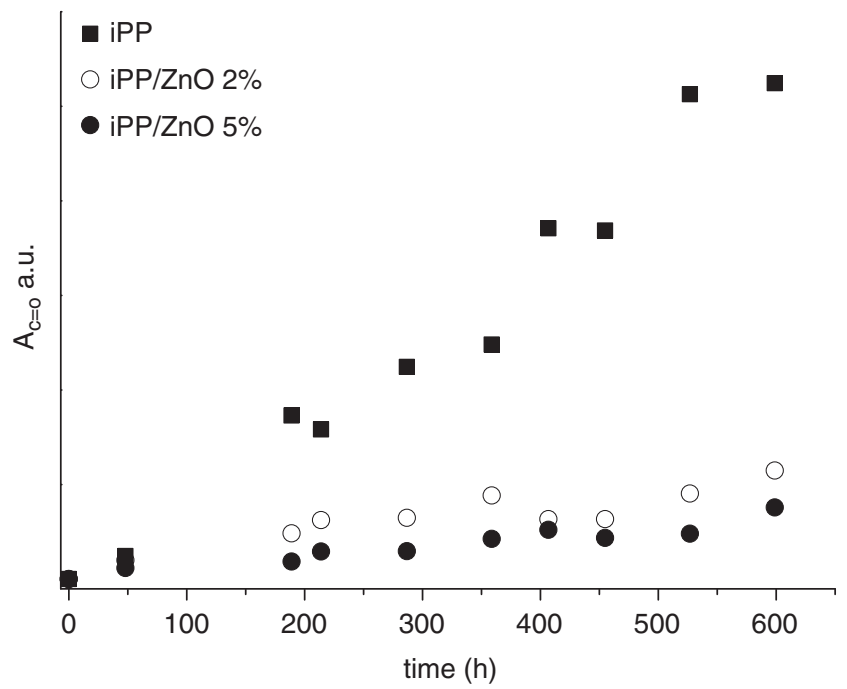

Figure 6 Evolution of the carbonyl index in the infrared spectra of iPP and the $\mathrm{IPP} / \mathrm{ZnO}$ composites as a function of aging.

Table 2 WAXD crystallinity index calculated at 0,300 and $600 \mathrm{~h}$ of UV exposure

\begin{tabular}{lccc}
\hline & $x_{c}(0 h)(\%)$ & $x_{c}(300 h)(\%)$ & $x_{c}(600 h)(\%)$ \\
\hline iPP & $46 \pm 2$ & $55 \pm 2$ & $54 \pm 2$ \\
iPP/ZnO 2\% & $45 \pm 2$ & $49 \pm 2$ & $56 \pm 2$ \\
iPP/ZnO 5\% & $47 \pm 2$ & $48 \pm 2$ & $55 \pm 2$ \\
\hline
\end{tabular}

Abbreviations: UV, ultraviolet; WAXD, wide-angle X-ray diffraction.

Table 3 Stress-strain parameters of iPP and the iPP/ZnO composites

\begin{tabular}{lccccc}
\hline & $E(M P a)$ & $\sigma_{y}(M P a)$ & $\varepsilon_{y}(\%)$ & $\sigma_{b}(M P a)$ & $\varepsilon_{b}(\%)$ \\
\hline iPP & $1350 \pm 100$ & $19 \pm 3$ & $7 \pm 2$ & $30 \pm 3$ & $890 \pm 65$ \\
iPP/ZnO 2\% & $1360 \pm 150$ & $19 \pm 2$ & $6 \pm 1$ & $20 \pm 4$ & $640 \pm 120$ \\
iPP/ZnO 5\% & $1430 \pm 166$ & $19 \pm 2$ & $6 \pm 1$ & $16 \pm 4$ & $500 \pm 120$
\end{tabular}

Abbreviation: ipp, isotactic polypropylene. 
The addition of $2 \%$ of $\mathrm{ZnO}$ does not affect the Young's modulus, and an increase of $\sim 6 \%$ is observed only for the $5 \%$ of $\mathrm{ZnO}$ sample. Note that the addition of the $\mathrm{ZnO}$ induces an increase in the errors on the measurements of the Young's modulus and elongation at break, which indicates instability during the deformation when the samples are submitted to tensile tests. No variation in the yield parameters is observed.

The results reported here do not show the so-claimed increase in mechanical properties that are usually observed in nanocomposites. This result should be because particles utilized have submicrometric dimensions; moreover, the presence of agglomerates, which were shown in the SEM micrographs, could serve as defect points that facilitate failure of the polymer. However, the composites still exhibit ductile behavior that differs from classical microcomposites. Studies are in progress for determining a compatibilizing agent between iPP and $\mathrm{ZnO}$ that is capable of increasing the interconnection between the

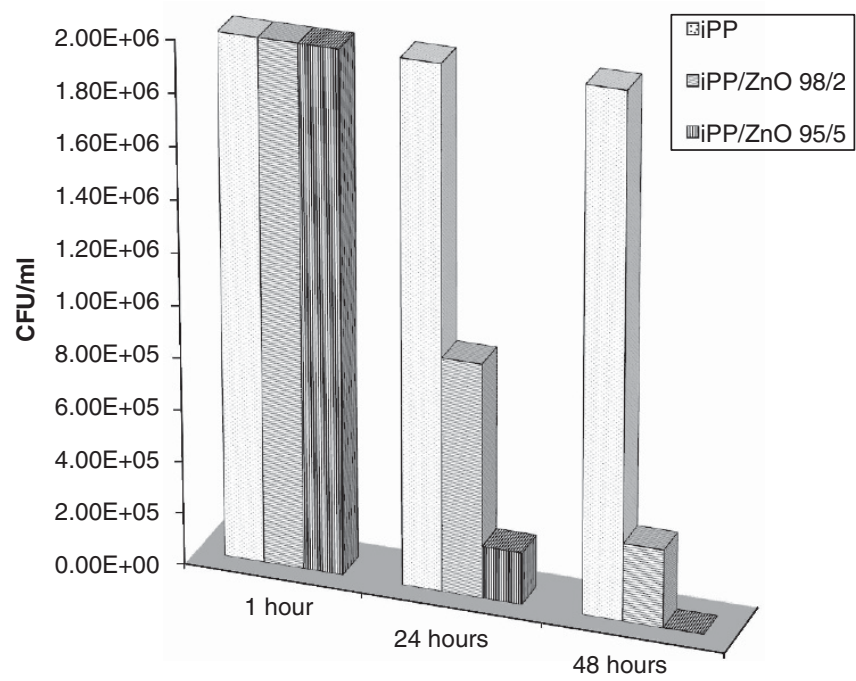

Figure 7 Effect of time and filler content in the iPP/ZnO composites on the antibacterial activity. phases and to obtain better mechanical properties, and this will be the subject of a forthcoming paper.

\section{Antibacterial activity}

In Figure 7, the antimicrobial effect against E. coli is presented as a function of time for the different composites. Without $\mathrm{ZnO}$ particles, the reference concentration of the micro-organism is measured to be $\sim 2 \times 10^{6}$. After $1 \mathrm{~h}$, no change in the concentration was observed for any of the samples. By increasing the time, a decrease in the E. coli concentration is observed for the composites. The effect is more evident for the $95 / 5 \mathrm{iPP} / \mathrm{ZnO}$ composite. A visual method for observing the biocide effect of the $\mathrm{ZnO}$ particles is shown in Figure 8. In Figure 8a, the bacterial growth of E. coli after $48 \mathrm{~h}$ of contact between the solution and neat iPP is obvious on the petri dish. In Figure $8 \mathrm{~b}$, it is evident that at the same contact time, no bacterial growth was observed for the $95 / 5 \mathrm{iPP} / \mathrm{ZnO}$ composite.

The quantitative bacterial reduction was examined by determining the percentage reduction (Equation 2), and the results are shown in Table 4. Neat iPP exhibits no bactericidal activity, and $R$ was observed to be zero at any time. The $95 / 5 \mathrm{iPP} / \mathrm{ZnO}$ composite exhibited maximum reduction after $48 \mathrm{~h}$ with a percentage of $99.9 \%$.

Although the antibacterial activity of $\mathrm{ZnO}$ is well-known, the mechanisms responsible for the antibacterial activity of metal oxide nanostructures are not fully understood; the proposed mechanisms

Table 4 Percent reduction of $E$. coli at different times of contact with films of iPP and the iPP composites

\begin{tabular}{lccc}
\hline & $\begin{array}{c}\text { Percent reduction } \\
(\mathrm{t}=1 \mathrm{~h})\end{array}$ & $\begin{array}{c}\text { Percent reduction } \\
(\mathrm{t}=24 \mathrm{~h})\end{array}$ & $\begin{array}{c}\text { Percent reduction } \\
(\mathrm{t}=48 \mathrm{~h})\end{array}$ \\
\hline iPP & 0 & 0 & 0 \\
iPP/ZnO & 0 & 55.1 & 90.2 \\
2 & & & \\
iPP/ZnO & 0 & 85.3 & 99.9 \\
5 & & & \\
\hline
\end{tabular}

Abbreviation: ipp, isotactic polypropylene.
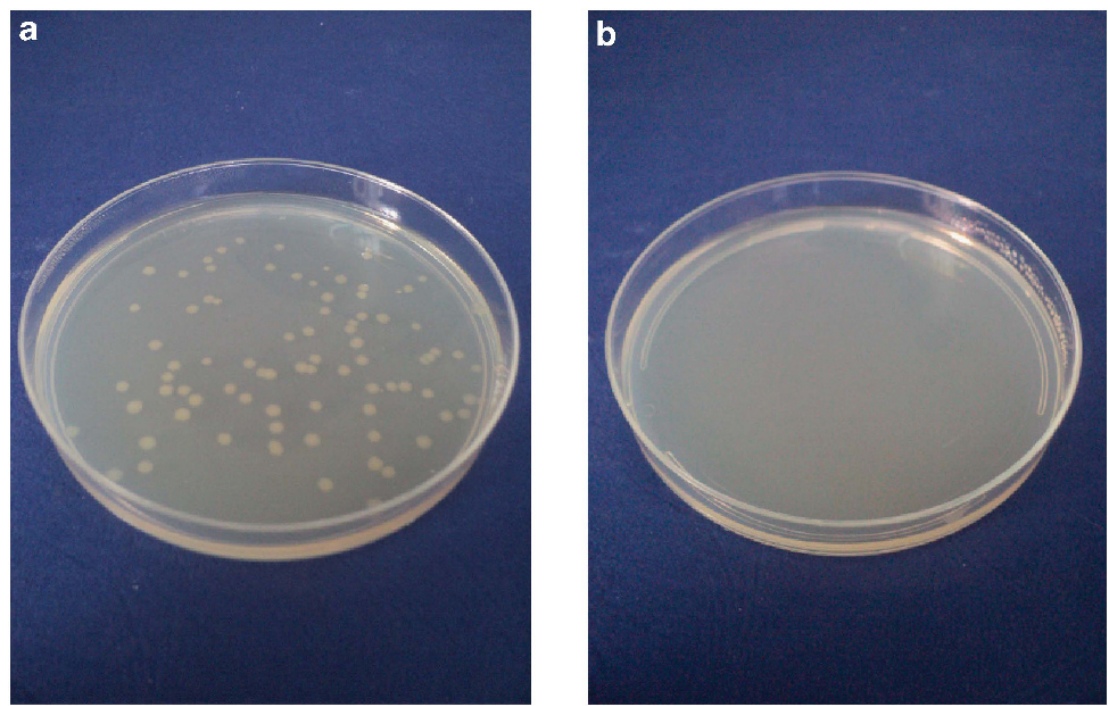

Figure 8 (a) Control plate without $\mathrm{ZnO}$ nanoparticles for measuring the growth of $E$. coli after $48 \mathrm{~h}$, (b) Antibacterial effect of $\mathrm{ZnO}$ nanoparticles in the $95 / 5$ iPP/ZnO composite after $48 \mathrm{~h}$. 
imply that active oxygen species are generated by $\mathrm{ZnO}$ particles, although there is no direct evidence from the results reported in the literature. $^{53}$

It has already been demonstrated that both nano-sized and micronsized $\mathrm{ZnO}$ suspensions are active in inhibiting the growth of bacteria and that the nano-sized $\mathrm{ZnO}$ suspension has greater activity than the micron-sized $\mathrm{ZnO}$ suspension. ${ }^{54}$ These results are consistent with the results reported in this paper, which also indicate that the submicron $\mathrm{ZnO}$ obtained by spray pyrolysis exhibits a substantial bactericidal effect that is similar to that obtained for particles with nanoscale dimensions.

\section{CONCLUSIONS}

In this paper, the influence of $\mathrm{ZnO}$ particles obtained by spray pyrolysis with submicron dimensions on the structure, morphology, photodegradation stability and thermal, mechanical, barrier and antibacterial properties of $\mathrm{iPP} / \mathrm{ZnO}$ composites prepared by melt mixing has been investigated. It was observed that despite the surface polarity mismatch between $\mathrm{iPP}$ and $\mathrm{ZnO}$, the extrusion process together with the particular particles utilized allows a composite with fair distribution of particles to be obtained.

The principal achievements of the novel composites with respect to pure iPP are (i) the antibacterial activity against E. coli; for the $95 / 5$ $\mathrm{iPP} / \mathrm{ZnO}$ composite, the percentage of bacteria reduced after $48 \mathrm{~h}$ is of 99.9\% and (ii) the significant improvements in the photodegradation resistance of iPP to UV irradiation.

Several other interesting results were obtained, including:

(1) The thermal stability of $\mathrm{iPP} / \mathrm{ZnO}$ composites is improved with respect to neat $\mathrm{iPP}$ and increases with the $\mathrm{ZnO}$ content;

(2) The iPP/ZnO composites remain ductile with an elongation at break value of $500 \%$, even with the incorporation of $5 \%$ of $\mathrm{ZnO}$. The addition of $2 \%$ of $\mathrm{ZnO}$ does not affect the modulus, whereas with the addition of $5 \%$ of $\mathrm{ZnO}$, an increase of $6 \%$ was observed. No variation in the yield parameters was observed.

\section{ACKNOWLEDGEMENTS}

The research described herein was supported by the bilateral project CNR/ CNRS (Italy-France) 'Antibacterial nanocomposites based on polyolephins for food packaging' and by COST Action FA0904 'Eco-sustainable food packaging based on polymer nanomaterials'.

1 Wang, C. X. \& Chen, S. H. L. Fragrance-release property of $\beta$-cyclodextrin inclusion compounds and their application in aromatherapy. J. Ind. Text. 34, 157-166 (2005)

2 Vigneshwaran, N., Kumar, S., Kathe, A. A., Varadarajan, P. V. \& Prasad, V. Functional finishing of cotton fabrics using zinc oxide-soluble starch nanocomposites. Nanotechnology 17, 5087-5095 (2006)

3 Silvestre, C., Duraccio, D. \& Cimmino, S. Food packaging based on polymer nanomaterials. Progr. Polym. Sci. 36, 1766-1782 (2011).

4 Gabriel, G. J., Som, A., Madkour, A. E., Eren, T. \& Tew, G. N. Infectious disease: connecting innate immunity to biocidal polymers. Mat. Sci. Eng. R: Reports 57, 28-64 (2007)

5 Anuvat Jangchud, N. E., Chonhenchob, V. \& Suppakul, P. Antimicrobial activity of cinnamaldehyde and eugenol and their activity after incorporation into cellulose-based packaging films. Packag. Technol. Sci. 25, 7-17 (2012).

6 Quintero, R. I., Rodriguez, F., Bruna, J., Guarda, A. \& Galotto, M. J. Cellulose Acetate Butyrate Nanocomposites with Antimicrobial Properties for Food Packaging (Published online in Wiley Online Library <http://www.wileyonlinelibrary.com> doi:10.1002/ pts. 1981 (2012)

7 Li, B., Yu, S., Hwang, J. Y. \& Shi, S. Antibacterial vermiculite nano-material. J. Miner. Mater. Charact. Eng. 1, 61-68 (2002).

8 Mũnoz-Bonilla, A. \& Fernandez-Garcia, M. Polymeric materials with antimicrobia activity. Prog. Polym. Sci. 37, 281-339 (2012).

9 Kumar, R. \& Münstedt, H. Silver ion release from antimicrobial polyamide/silver composites. Biomaterials 26, 2081-2088 (2005).
10 Liau, S. Y., Read, D. C., Pugh, W. J., Furr, J. R. \& Russell, A. D. Interaction of silve nitrate with readily identifiable groups: relationship to the antibacterial action of silver ions. Lett. Appl. Microbiol. 25, 279-283 (1997).

11 Fujishima, A., Rao, T. N. \& Tryk, D. A. Titanium dioxide photocatalysis. J. Photochem Photobiol. C 1, 1-21 (2000).

12 Stoimenov, P. K., Klinger, R. L., Marchin, G. L. \& Klabunde, K. J. Metal oxide nanoparticles as bactericidal agents. Languimuir 18, 6679-6686 (2002).

13 Yamamoto, $\mathrm{O}$. Influence of particle size on the antibacterial activity of zinc oxide. Int. J Inorg. Mater. 3, 643-646 (2001).

14 Jones, N., Ray, B., Ranjit, K. T. \& Manna, A. C. Antibacterial activity of ZnO nanoparticle suspensions on a broad spectrum of microorganisms. FEMS Microbiol. Lett. 279, 71-76 (2008).

15 Padmavathy, N. \& Vijayaraghavan, R. Enhanced bioactivity of ZnO nanoparticles-an antimicrobial study. Sci. Technol. Adv. Mat. 9, 035004-035010 (2008).

16 Dickson, R. M. \& Lyon, L. A. Unidirectional plasmon propagation in metallic nanowires J. Phy. Chem. 104, 6095-6098 (2000).

17 Tjong, S. C. \& Liang, G. D. Electrical properties of low-density polyethylene/ZnO nanocomposites. Mat. Chem. Phys. 100, 1-5 (2006).

18 Droval, G., Aranberri, I., Bilbao, A., German, L., Verelst, M. \& Dexpert-Ghys, J. Antimicrobial activity of nanocomposites: poly(amide) 6 and low density poly(ethylene) filled with zinc oxide. e-polymers 128, 1-13 (2008).

19 Zhao, H. \& Li, R. A study on the photo-degradation of zinc oxide ( $\mathrm{ZnO}$ ) filled polypropylene nanocomposites. Polymer 47, 3207-3217 (2006)

20 Huang, C., Chen, S. \& Wei, W. C. J. Processing and property improvement of polymeric composites with added $\mathrm{ZnO}$ nanoparticles through microinjection molding. J. Appl. Polym. Sci. 102, 6009-6016 (2006).

21 Lepot, N., Van Bael, M. K., Van den Rul, H., D'Haen, J., Peeters, R., Franco, D. \& Mullens, J. Influence of incorporation of $\mathrm{ZnO}$ nanoparticles and biaxial orientation on mechanical and oxygen barrier properties of polypropylene films for food packaging. J. Appl. Polym. Sci. 120, 1616-1623 (2011).

22 Chandramouleeswaran, S., Mhaske, S. T., Kathe, A. A., Varadarajan, P. V., Prasad, V. \& Vigneshwaran, N. Functional behaviour of polypropylene/ZnO-soluble starch nanocomposites. Nanotechnology 18, 8 (2007).

23 Tang, J., Wang, Y., Liu, H. \& Belfiore, A. Effects of organic nucleating agents and zinc oxide nanoparticles on isotactic polypropylene crystallization. Polymer 45 , 2081-2091 (2004)

24 Fernandes, D. M. Winkler Hechenleitner, A. A., Lima, S. M., Andrade, L. H. C., Caires, A. R. L. \& Gómez Pineda, E. A. Preparation, characterization, and photoluminescence study of PVA/ZnO nanocomposite films. Mater. Chem. Phys. 128, 371-376 (2011).

25 Erem, A. D . Ozcan, G. \& Skrifvars, M. Antibacterial activity of PA6/ZnO nanocomposite fibers. Text. Res. J. 81, 1638-1646 (2011).

26 Rajendran, R., Balakumar, C., Ahammed, H. A. M., Jayakumar, S., Vaideki, K. \& Rajesh, E. M. Use of zinc oxide nano particles for production of antimicrobial textiles. Sci. Technol. 2, 202-208 (2010).

27 Vassiliou, A., Vassiliou, D., Bikiaris, A., Chrissafis, K., Paraskevopoulos, K. M., Stavrev, S. Y. \& Docoslis, A. Nanocomposites of isotactic polypropylene with carbon nanoparticles exhibiting enhanced stiffness, thermal stability and gas barrier properties. Compos. Sci. Technol. 68, 933-943 (2008).

28 Ellis, T. S. \& D'Angelo, J. S. Thermal and mechanical properties of a polypropylene nanocomposite. J. Appl. Polym. Sci. 90, 1639-1647 (2003).

29 Galgali, G., Agarwal, S. \& Lele, A. Effect of clay orientation on the tensile modulus of polypropylene-nanoclay composites. Polymer 45, 6059-6069 (2004).

30 Lee, J., Son, S. \& Hong, S. Characterization of protein-coated polypropylene films as a novel composite structure for active food packaging application. J. Food Eng. 86, 484-493 (2008)

31 Manikantan, M. R. \& Varadharaju, N. Preparation and properties of polypropylenebased nanocomposite films for food packaging. Packag. Technol. Sci. 24, 191-209 (2011).

32 Kato, M., Usuki, A., Hasegawa, N., Okamoto, H. \& Kawasumi, M. Development and applications of polyolefin- and rubber-clay nanocomposites. Polym. J. 43, 583-593 (2011)

33 Yuan, W., Guo, M., Miao, Z. \& Liu, Y. Influence of maleic anhydride grafted polypropylene on the dispersion of clay in polypropylene/clay nanocomposites. Polym. J. 42, 745-751 (2010).

34 Rossignol, C., Verelst, M., Dexpert-Ghys, J. \& Rul, S. Synthesis of undoped ZnO nanoparticles by spray pyrolysis. Adv. Sci. Tech. 45, 237-241 (2006).

35 Pratsinis, S. E. \& Vemury, S. Particle formation in gases: a review. Powd. Technol. 88, 267-273 (1996)

36 Reuge, N., Dexpert-Ghys, J., Verelst, M. \& Caussat, B. Y203:Eu micronic particles synthesised by spray pyrolysis: global modelling and optimisation of the evaporation stage. Chem. Eng. Process. 47, 731-743 (2008).

37 Minogianni, C., Gatos, K. G. \& Galiotis, G. Estimation of crystallinity in isotropic isotactic polypropylene with raman spectroscopy. Appl. Spectrosc. 59, 1141-1147 (2005).

38 Brus, L. Electronic wave functions in semiconductor clusters: experiment and theory. J. Phys, Chem. 90, 2555-2560 (1986).

39 Osawa, Z. Role of metals and metal-deactivators in polymer degradation. Polym Degrad. Stab. 20, 203 (1988).

40 Kotsilkova, R., Ivanov, E., Krusteva, E. Silvestre, C., Cimmino, S. \& Duraccio, D. Isotactic polypropylene composites reinforced with multiwall carbon nanotubes, part 2 thermal and mechanical properties related to the structure. J. Appl. Polym. Sci. 115 3576 (2010).

41 Allen, N. S. \& Edge, M. Fundamentals of Polymer Degradation and Stabilization Ch. 4 (Elsevier Applied Science, Elsevier Science Publishers, London, UK, 1992). 
42 Qin, H., Zhang, S., Liu, H., Xie, S., Yang, M. \& Shen, D. Photo-oxidative degradation of polypropylene/montmorillonite nanocomposites. Polymer 46, 3149-3156 (2005).

43 Morlat, S., Mailhot, B., Gonzalez, D. \& Gardette, J. L. Photo-oxidation of polypropylene/ montmorillonite nanocomposites. 1 . influence of nanoclay and compatibilizing agent. Chem. Mater. 16, 377-383 (2004).

44 Philippart, J. L., Sinturel, C., Arnaud, R. \& Gardette, J. L. Influence of the exposure parameters on the mechanism of photooxidation of polypropylene. Polym. Degrad. Stab. 64, 213-225 (1999).

45 Obadal, M., Cermak, R., Raab, M., Verney, V., Commereuc, S. \& Fraises, F. Structure evolution of $\alpha$-and $\beta$-polypropylenes upon UV irradiation: a multiscale comparison. Polym. Degrad. Stab. 88, 532-539 (2005).

46 Kotek, J., Kelnar, I., Studenovsky, M. \& Baldrian, J. Chlorosulfonated polypropylene: preparation and its application as a coupling agent in polypropylene-clay nanocomposites. Polymer 46, 4876-4881 (2005).

47 Yang, R., Li, Y. \& Yu, J. Photo-stabilization of linear low density polyethylene by inorganic nano-particles. Polym. Degrad. Stab. 88, 168-174 (2005).
48 Terselius, B., Gedde, U. W. \& Jansson, J. F. Structure and morphology of thermally oxidized high density polyethylene pipes. Polym. Eng. Sci. 22, 422-431 (1982).

49 Scheirs, J., Bigger, S. W. \& Delatycki, O. Characterizing the solid-state thermal oxidation of poly (ethylene oxide) powder. Polymer 32, 2014-2019 (1991).

50 Kaczmarek, H. Changes to polymer morphology caused by UV irradiation: 1. Surface damage. Polymer 37, 189-194 (1996).

51 Allen, N. S., Edge, M., Corrales, T., Shah, M., Holdsworth, D., Catalina, F., Peinado, C. \& Collar, E. P. Thermal and photooxidation of polypropylene influence of long-term ambient oxidation: spectroscopic, thermal and light scattering studies. Polymer 37, 2323-2333 (1996).

52 Wunderlich, B. Macromolecular Physics Vol. 2 (Academic Press, New York, 1976).

53 Yamamoto, O., Sawai, J. \& Sasamoto, T. Change in antibacterial characteristics with doping amount of $\mathrm{ZnO}$ in $\mathrm{MgO}-\mathrm{ZnO}$ solid solution. Int. J. Inorg. Mater. 2, 451-454 (2000).

54 Zhang, L., Jiang, Y., Ding, Y., Daskalakis, N., Jeuken, L., Povey, M., O’Neill, A. J. \& York, D. W. Mechanistic investigation into antibacterial behaviour of suspensions of ZnO nanoparticles against E. coli. J. Nanopart. Res. 12, 1625-1636 (2010). 